$\angle$ Research Square
Preprints are preliminary reports that have not undergone peer review.

They should not be considered conclusive, used to inform clinical practice, or referenced by the media as validated information.

\title{
Acceptability of saliva-based HIVST among men who have sex with men (MSM) and transgender women (TGW) in Russia: a qualitative study
}

Peter Meylakhs ( $\nabla$ peter.meylakhs@gmail.com )

National Research University Higher School of Economics: Nacional'nyj issledovatel'skij universitet Vyssaa skola ekonomiki https://orcid.org/0000-0002-3029-9918

\section{Anastasia Meylakhs}

National Research University Higher School of Economics - Saint Petersburg: Nacional'nyj issledovatel'skij universitet Vyssaa skola ekonomiki - Sankt-Peterburg

Arsen Davitadze

National Research University Higher School of Economics - Saint Petersburg: Nacional'nyj issledovatel'skij universitet Vyssaa skola ekonomiki - Sankt-Peterburg

\section{Original Research}

Keywords: HIV self-testing, HIV self-testing acceptability, men who have sex with men, transgender women, Russia

Posted Date: February 10th, 2021

DOl: https://doi.org/10.21203/rs.3.rs-178133/v1

License: (9) This work is licensed under a Creative Commons Attribution 4.0 International License. Read Full License 


\section{Abstract}

The COVID-19 pandemic increased actuality of HIV self-testing (HIVST). Men who have sex with men (MSM) and transgender women (TGW) in Russia are highly stigmatized populations vulnerable to HIV infection and hard to reach with facility-based testing strategies. The study explored acceptability of HIV self-testing (HIVST) among these key groups in Russia. 32 semi-structured interviews with MSM and 3 TGW women from 5 Russian cities who underwent HIVST were conducted. Benefits of HIVST included ease of use, convenience and confidentiality. Confidentiality helped participants to avoid stigma related to their identity thus empowering them in conditions of high stigmatization of LGBTQ-people.

Participants expressed concerns about accuracy of saliva-based HIVST and lack of counseling in case of reactive result. Our results suggest high acceptability of HIVST among Russian MSM and TGW and indicate that increase in HIVST uptake could be facilitated by popularization of HIVST and addressing the participants' concerns.

\section{Introduction}

The COVID-19 pandemic that made access to facility-based testing more difficult (CDC, 2020), especially for key populations (AFEW 2020), has increased actuality of HIV self-testing (HIVST) as recognized by The Centers for Disease Control and Prevention (CDC, 2020) and The International AIDS Society (IAS) (2020). Men who have sex with men (MSM) and transgender women (TGW) are key populations disproportionally affected by HIV (Brito MO et al., 2020; Figueroa C et al., 2015; Stannah J et al., 2019) in many countries and one of the hardest groups to reach with standard testing strategies (Clark JL et al., 2014; Gama A et al., 2017; Iribarren SJ et al., 2018). While in recent years HIV epidemic in Russia has been largely driven by parenteral route among people who inject drugs (PWID) and heterosexual transmission (Beyrer C et al., 2017; Pokrovsky V et al., 2017; Stuikyte R et al., 2019) MSM and TGW remain highly vulnerable to HIV infection. HIV prevalence among MSM in various Russian cities has been estimated to be at 3.5-23\% (Berg RC et al., 2017; Plavinskiy SL et al., 2018; Wirtz AL et al., 2016). MSM and TGW in Russia face stigma and discrimination (Amirkhanian YA et al., 2006; Berg RC et al., 2017; Buyantueva R, 2018; Vasquez C et al., 2013). MSM- and TGW-related stigma was found to be associated by lower levels of testing (Hakim AJ et al., 2018; Stannah J et al., 2019; Wirtz AL et al., 2014), especially in traditional clinic-based settings (Campbell CK et al., 2018). A large respondent-driven sample study conducted in 2016 in Moscow among MSM underlines crucial drawbacks in the HIV testing and care continuum (Wirtz AL et al., 2016). The study showed that more than $75 \%$ of HIV infected participants ( $23 \%$ of the sample) had been unaware of their seropositive status prior to the study, thus highlighting poor coverage of HIV testing. Wirtz and colleagues conclude that although HIV testing is publicly available in Russia, it does not reach those at higher risk of HIV-infection, which stresses the need to apply novel approaches to HIV-testing among MSM and TG in Russia along with the fight against stigma and discrimination towards these key groups.

HIV self-testing (HIVST) is a relatively new and promising approach to HIV testing, whose importance was recognized by the World Health Organization (WHO) already in 2014 (WHO / Consolidated Guidelines on 
HIV Testing Services, 2014). HIVST is usually defined as a form of HIV testing that involves selfadministered collecting of blood or saliva sample, placing it into a developer vial and obtaining results within a short period of time (Napierala Mavedzenge et al., 2013). Existing research provides extensive evidence of high accuracy of HIVST among MSM and TGW (Lippman SA et al., 2016; Witzel TC et al., 2019). Also, across setting studies have demonstrated high acceptability of and intention to use HIVST among MSM, TGW, and other key populations, stressing its capacity to encourage repeated and first-time testing among hard-to-reach populations (Figueroa C et al., 2015; Freeman AE et al., 2018; Greacen T et al., 2013; Krause et al., 2013; Oldenburg CE et al., 2017; Rosengren AL et al., 2016; Wood BR et al., 2014).

Additionally, there is evidence that HIVST may promote mutual partner testing and thus avert condomless sex between discordant partners, increase awareness of risk and incorporate safer sex practices (Lippman SA et al., 2018; Wood BR et al., 2014; Zhu X et al., 2019), as well as generally increase HIV testing frequency among MSM (Bavinton BR et al., 2013; Witzel TC, Weatherburn P, et al., 2020; Zhang et al., 2017).

Another key advantage of HIVST is its potential to be empowering for MSM (Figueroa C et al., 2015; Freeman AE et al., 2018; Krause et al., 2013; Wood BR et al., 2014). Unlike the facility-based HIV testing, which is constrained by perceived lack of privacy and fear of discrimination, HIVST provides an opportunity to highly confidential testing thus providing more power over one's own health. Self-testing has a great potential to become a more effective HIV testing approach compared to "traditional" facilitybased testing (Figueroa C et al., 2015; Iribarren SJ et al., 2018), with regards to MSM and TGW, who are reluctant to test on HIV in public settings (Figueroa $C$ et al., 2015; Freeman AE et al., 2018; Krause et al., 2013; Pai NP et al., 2013; Witzel TC, Weatherburn P, et al., 2020).

However, despite these advantages, there are some major concerns related to HIVST, particularly unsupervised, suggesting that it may have potentially adverse consequences. The most important concerns are associated with the lack of counseling, which may cause bad linkage to care, missed opportunities to get information about risk prevention and psychological difficulties related to receiving positive test result privately (Allais L \& Venter F, 2014; Frye V et al., 2015; Walensky RP \& Bassett IV, 2011; Wood BR et al., 2014). Moreover, as window period of HIVST is longer compared to "traditional" bloodbased tests, possibility of false-negative result is another issue, as it may cause groundless confidence, prevent patient from receiving a necessary treatment and promote condomless sex (Bustamante MJ et al., 2017; Freeman AE et al., 2018; Pai NP et al., 2013; Wei C et al., 2018; Wood BR et al., 2014). Although recent studies stress that no adverse effects (such as a suicide) of HIVST have yet been observed (Martinez et al., 2014), more research is needed to address perceptions and concerns of MSM and TGW towards self-testing in diverse settings. While in the most parts of the world research on HIVST is consistently increasing, to our knowledge, this is the first study of HIVST in Russia. The current study aims to explore acceptance of HIVST among Russian MSM and TGW as well as to analyze various concerns related with HIVST among these key groups.

\section{Methods}




\section{Sampling and Recruitment}

The current study is based on a three-year non-commercial campaign providing free HIVST to MSM, which informed the sampling strategy used in the study. As the campaign covered five Russian cities, respondents were recruited among projects' participants residing in Moscow, Saint-Petersburg, Ekaterinburg, Omsk and Oryol - cities, which differ in several significant ways. First, size-wise SaintPetersburg and Moscow are two largest cities in the country, Ekaterinburg and Omsk are average-sized Russian cities, and, finally, Oryol is a relatively small town, which had a population of slightly over 300 thousand people in 2017. Second, according to both official statistics and recent research, HIV rates vary greatly from region to region in Russia, with Moscow and Saint-Petersburg having one of the highest levels of the epidemic in the country (HIV Infection in the Russian Federation, 2014 [Internet]. [Cited 2014 Nov 4]. Available from: Http://Www.Hivrussia.Ru/Files/SpravkaHIV2014.Pdf. Accessed 1 April 2018, n.d.). Third, although HIV testing is nationally provided by Federal AIDS centers, which are present in every city included in the sample, larger cities provide more opportunities to HIV testing as well as to having an access to information about HIV in general due to the presence of non-governmental outreach programs and LGBTQ-oriented NGOs.

Notably, cities included in the study sample differ from each other in respect to existing research on HIV: previous studies on HIV-related issues have been mostly concentrated in Saint-Petersburg and Moscow, although there is evidence suggesting that not only HIV prevalence rates but also factors associated with risk practices related to HIV may differ from city to city in Russia (Berg et al., 2017).

To be eligible for the study participants had to be aged 18 years or older, undergo HIV self-testing with HIVST kits (saliva OraQuick Rapid HIV-1/2 Antibody Test) that were distributed during the campaign and self-identify as "gay", "bisexual", or TGW. Participants were recruited from February to April, 2018. After the initial contact with the MSM-oriented NGO that organized the HIVST campaign (hereafter NGO) was established, a first wave of recruitment started. From the beginning of the HIVST campaign all the participants were asked to voluntarily and anonymously fill in a short online-questionnaire after selftesting in order to share their test results and report testing and risk behaviors. They were also asked to leave their email contacts for possible further communication, if they wished to do so. All participants who had left their e-mail addresses were sent invitation letters, which included description of study goals, terms of confidentiality, incentives and invitation to online-interview. Although more than 90 people replied with preliminary consent, most of them received HIVST kits in Moscow and Saint-Petersburg and were HIV-negative. As we aimed to find both HIV positive and HIV-negative participants from each of the five cities included in the sample, we only contacted some of those who responded, which resulted in 16 MSM who gave their contact and agreed to participate in online-interview.

In a second wave of recruiting NGO established contacts with social workers who coordinated the campaign in each of the five cities. The social workers were instructed to invite eligible HIVST kit receivers to participate in the study. After obtaining a preliminary consent from potential participants, recruiters 
referred participants contacts to the NGO coordinator, who, in turn, referred participant to the researchers. This resulted in another $19 \mathrm{MSM}$ and TGW who agreed to interview.

\section{Data Collection}

Semi-structured interviews that lasted 30-60 minutes were conducted remotely using Voice over Internet Protocol (VolP) technologies without video-connection. Each subject received a 500 rubles (about \$9) incentive payment after the interview. Participants were able to choose a convenient day and time for the interview, as well as a means of communication (Skype, WhatsApp, Telegram, etc.). After an initial consent for the interview had been obtained from a participant and interview procedure and preliminary date for the interview had been chosen, the participant was sent an informed consent and was asked to read it carefully before the interview. At the beginning of each interview researcher made sure that participant had no more questions and had read the informed consent and agreed with it. All interviews were audio-recorded with participants' consent. Interviews were conducted by PM, AM and a field worker who had been trained to carry out interviews using a guide designed for the study.

The interview guide covered the following topics: socio-demographic characteristics of informants, lifetime history of HIV testing, participant's assessment of HIV self-testing, sexual behavior and substance use. The guide for seropositive informants included additional questions about linkage to care and HIV care experience.

The study was reviewed and approved by the Ethical Committee of Saint-Petersburg Association of Sociologists. We use pseudonyms for informants.

\section{Data Analysis}

Interviews were transcribed verbatim and the transcripts were analyzed using MAXQDA software (VERBI Software, 2019). Two research team members (PM and AM) familiarized themselves with the transcripts and developed an initial coding framework though discussion. Thematic analysis (Braun $\vee$ et al., 2019) was applied to identify common and differing patterns across participants' narratives describing their experience of and attitudes toward self-testing. The initial coding framework included themes such as self-testing performance experience, problems associated with self-testing etc. During further analysis nested sub-themes emerged, which were analyzed thematically and compared across the sample. The coders regularly met to discuss the emerging results and disputes in interpretation were resolved on a consensus basis.

\section{Results}

As presented in Table 1, the total sample consisted of thirty-two MSM, who identified themselves as "gay" or "bisexual", and three participants who self-identified as transgender women during the interview residing in Moscow (34\%), Saint-Petersburg (17\%), Ekaterinburg (17\%), Omsk (23\%) and Oryol (9\%) at the time of the study. Participants' age varied from 18 to 52 years with a median age of 32 years $(S D=9)$. 
Study participants were highly educated $(60 \%$ had higher education and $17 \%$ were attending university at the time of the study) and mostly working (80\%). Twenty-three participants $(66 \%)$ tested negative, while twelve participants (34\%) tested HIV-positive and already received confirmation of their seropositive status at the time of the interview.

\begin{tabular}{|c|c|}
\hline & Total sample $(n=35), \%$ \\
\hline \multicolumn{2}{|l|}{ Gender identity } \\
\hline Man & 91 \\
\hline Transgender Woman & 9 \\
\hline Total & 100 \\
\hline Median age (SD), years & $32(9)$ \\
\hline \multicolumn{2}{|l|}{ City } \\
\hline Moscow & 34 \\
\hline Saint-Petersburg & 17 \\
\hline Ekaterinburg & 17 \\
\hline Omsk & 23 \\
\hline Oryol & 9 \\
\hline Total & 100 \\
\hline \multicolumn{2}{|l|}{ Level of education } \\
\hline Primary & 3 \\
\hline Secondary & 3 \\
\hline Vocational school & 14 \\
\hline Uncompleted higher education & 3 \\
\hline University student & 17 \\
\hline Higher education or degree & 60 \\
\hline Total & 100 \\
\hline Employed & 80 \\
\hline Unemployed & 20 \\
\hline Total & 100 \\
\hline \multicolumn{2}{|l|}{ HIV status } \\
\hline Negative & 66 \\
\hline Positive & 34 \\
\hline Total & 100 \\
\hline
\end{tabular}

Most of MSM and TGW (83\%) had tested for HIV prior to self-testing either deliberately or as a 'side' procedure within a more general health check-up required by military enlistment office, as part of 
employment process, before surgery or blood donation. Condom use was inconsistent - only about one in four informants (25\%) (data not shown) reported always using condoms when having sex for the past year. The patterns of sexual behavior varied substantially among the sample: some MSM and TGW had single and exclusive long-lasting relationships during the past years, while others reported frequent onenight stands or having 'occasional' partners along the stable ones.

In what follows we will describe three main themes identified during the interview analysis: potential benefits of HIVST, its potential drawbacks, and experience of getting a reactive result of HIVST.

\section{Benefits of HIVST}

HIV self-testing was generally acceptable to study participants. Most participants reported high interest and intention to use it in the future describing saliva-based self-testing as easy, convenient and highly confidential. We first start with describing these three main benefits outlined by the majority of MSM and TGW during interviews.

\section{1) Ease of Use}

Although conditions surrounding self-testing performance varied substantially among the study participants in terms of location of testing, presence of other people such as partners, friends or social workers and emotional state during testing, all informants perceived saliva-based self-testing as being easy to use, intuitive and straightforward.

"It was all quite simple. It was impossible to mess it up somehow. It is simple to take out this thing, stick it under the gum so you don't touch your cheeks; as I recall, the instructions told to dip it in the liquid there was some kind of solution - and to wait." (Informant \#21, MSM, 23 y.o., HIV-, Ekaterinburg)

According to informants, a clear and simple instruction sheet - sometimes described as "foolproof" - was a key to non-problematic performance of self-tests. However, participants reported reading it carefully with many of them re-reading it several times, which was often attributed to the perceived importance of accurate administration of self-testing as well as to fear of making something wrong:

"In general, it was all described in quite - quite a lot of detail, and quite clearly; I mean, I had no trouble with it. The only thing is that, due to some kind of my personal anxiety... because... it's not like it was a step of great responsibility, but it's like... I don't know. I re-read everything several times, to make sure I would do it all correctly. And then, when I got my result, I re-read everything a few more times, recalling how I had done it all, recreating the image in my head, to have a clear understanding that I have done everything correctly" (Informant \#31, MSM, 21 y.o., HIV+, Moscow)

\section{2) Convenience}

Convenience of self-testing was described by our participants in terms of time-saving, perceived comfort of testing and opportunity to perform the test in any setting, including one's home. When asked about 
their opinion regarding the time required to self-test, some participants compared it with pregnancy tests and stressed that "twenty minutes - I think, if I am not mistaken - is not misused if spent to get some information about your own health" (Informant \#38, MSM, 41 y.o., HIV-, Moscow).

Discussing the convenience of self-testing many MSM and TGW compared it to their experience of 'traditional' testing for HIV, thus underlining the advantages of HIVST. While for some participants 'traditional' blood-based testing was associated with psychological issues such as fear of injections, painfulness of blood-based tests and psychologically challenging long period of waiting for the test results, others noted more practical drawbacks like the amount of time required to get to the testing facility, long waiting time in lines, as well as the necessity to fit in facility-based HIV testing into one's working schedule:

"For example, I get up very early, and I go to bed very early; I seldom have days off. And in those cases when I self-administered the test, I got up in the morning, slid the stick, collected the saliva, got it all ready. While waiting for the result, I was getting ready for work. It was more convenient for me than to take a day off and go to the AIDS center; when I went to the clinic, it took more time" (Informant \#18, TGW, 21 y.o., $\mathrm{HIV}+$, Omsk)

While the difficulty of incorporating HIV testing into daily routine was mentioned by participants as one of the main barriers to regular testing, HIVST was presented as a possible solution to the problem:

"The advantage (of self-testing) is that you shorten the path between deciding to go and take a test to the moment when you do the test" (Informant \#33, MSM, 25 y.o., Omsk, HIV+)

Additionally, most participants perceived an opportunity to test at home as a big benefit of HIVST, suggesting that it makes testing more calm and comfortable as well as generates less anxiety.

\section{3) Confidentiality}

One of the main advantages of self-testing noted by MSM and TGW was the possibility to test for HIV confidentially. Many participants mentioned existing stigma related to HIV among the main concerns when discussing facility-based testing:

"The advantage [of self-testing], I would say is that a person can stay at home and not worry that he has been seen in some kind of center, where he happens to be doing a blood test for AIDS. Unfortunately, in our country such people are given funny looks." (Informant \#23, MSM, 48 y.o., Oryol, HIV+)

Perceived HIV stigma was particularly articulated by some MSM and TGW residing in smaller cities, where visiting HIV testing facilities was often described in terms of embarrassment, shame and discomfort. Along the stigma of HIV, stigma related to gay identity was also articulated and suggested to be a barrier for facility-based testing for HIV among MSM and TGW: 
"I think that it is like an additional barrier for many - going to some kind of a regular state hospital and possibly encounter homophobic or some other irrational views. And this, too, is such a considerable barrier." (Informant \#25, MSM, 26 y.o., Oryol, HIV+)

Stressing the possibility to avoid stigma by using HIVST some participants associated it with having more control over their health and, therefore, the empowering potential of self-testing:

"To me, it seems right, because it seems that it is a very good project for Russia particularly. Because you yourself know what sort of environment we live in, and such projects help people feel protected and secure." (Informant \#7, MSM, 19 y.o., Moscow, HIV-)

Most seropositive informants when sharing their experience of self-testing pointed out that HIVST provided them an opportunity to 'prepare' (both emotionally and to avoid stigma) for going to medical facilities. The concept of 'preparation' involved having time to accept the high possibility of being HIVinfected before linking to care, which made this way of testing more acceptable to them:

"Of course, at home. First, you should test at home, I think. And then, if it shows a positive result at home, you can go to a medical institution, as you still are preparing yourself for getting a positive result. When a person is found to be positive in a medical institution and he is, all of a sudden, told that he is positive - I think that this isn't right. Not all doctors can come over and whisper it in your ear - and there will be people around you." (Informant \#23, MSM, 48 y.o., Oryol, HIV+)

\section{Drawbacks of HIVST}

\section{1) Concerns regarding HIVST accuracy}

Possible lack of accuracy was perceived by most MSM and TGW as the main disadvantage of salivabased self-testing. Many participants shared their concerns regarding the trustworthiness of HIVST results naming sensitivity and specificity of HIVST as the main source of concern. As the following quote illustrates: "I was apprehensive [...] that there was a possibility that it might show inaccurate results» (Informant \#36, MSM, 34 y.o., Moscow, HIV+).

Additionally, for some participants the lack of trust for HIVST result was associated with scarcity of available and reliable information about saliva-based HIVST. Several MSM and TGW mentioned that novelty of the technology and confusion regarding its working principles were particularly crucial for their mistrust:

"Well, I am a bit suspicious of this tool [saliva-based HIVST]. Because I don't have an understanding of what's going on when testing is taking place. This is what causes me to doubt it." (Informant \#20, MSM, 31 y.o., Ekaterinburg, HIV-)

Other participants explained the lack of trust for HIVST results in terms of the absence of institutional attributes of healthcare-related testing, such as an official paper with a test result or presence of doctors: 
"It's still just a box with a plastic thing that you take out and kind of measure something. It doesn't seem very reliable as there are no people in white robes - something along these lines. So, there is really some kind of... when a doctor says something to me, he is, like, a professional, it's all for real - and here, I kind of just got tested myself." (Informant \#24, MSM, 33 y.o., Oryol, HIV-)

However, as he continues, such institutional signals of trust are only lacking until HIVST becomes more widespread and usual, comparing it with pregnancy tests:

"But I think that if, like, a person did this all the time or something and knew what it was about, he would trust it. It is similar to when girls do a pregnancy test - they put a certain trust in this test. I mean, it's the same here - it seems that it's all just because it's a new thing that people haven't got used to yet." (Informant \#24, MSM, 33 y.o., Oryol, HIV-)

Many informants whose HIVST turned positive described a problem associated with a reactive result interpretation. It was caused by a visual variability of a self-test result in terms of density and sharpness of the two lines indicating a positive result. For example, low visibility of the second line or some blur often contributed to participants' mistrust regarding the result accuracy, and was interpreted as a defect of particular kit or as invalid result, and led to repeated testing using another HIVST kit or facility-based testing options.

\section{2) Concerns regarding a reactive result}

Some of those informants who tested negative mentioned fear of receiving a reactive result as one of main of HIVST drawbacks; however, the reasons for this fear were different. For several participants it was associated with the accuracy of HIVST result; thus they described the psychological challenge of receiving a reactive result in terms of having to confirm their serostatus via facility-based testing, which would take them some additional waiting time with corresponding uncertainty:

Interviewer: "That is, you mean that it is easier to learn the accurate facility-based result and not to be doubtful?"

Informant: "Yes; I think yes - doubt is, after all, a hard thing to experience." (Informant \#36, MSM, 34 y.o., Moscow, HIV+).

Other participants perceived reactive result as a highly reliable confirmation of being HIV-infected and, therefore, were afraid of lack of immediate psychological support. Notably, the perception of psychological support was not medicalized and involved presence of any 'trusted' person - someone who is aware of LGBTQ-identity of participant, including a friend, partner or a social worker. Some type of immediate personal support was highlighted by these informants as a necessary prerequisite for effective linkage to care:

"I know myself well enough to be sure that I would not have gone anywhere after that, and that I would not have done anything after that. I would have just thrown it away; I would have kept it all inside myself 
- what the test showed, that I am sick - and I would not have done anything. It's just that they explained everything to me at that moment, I was supported - which is necessary in such a case, absolutely necessary" (Informant \#36, MSM, 34 y.o., Moscow, HIV+).

\section{Discussion}

The study demonstrates high acceptability of HIVST among MSM and TGW, who expressed strong interest and intention to use HIVST in the future, describing it as easy to use, confidential and convenient method of testing, especially for those experiencing stigma and discrimination. These findings are in line with the existing literature on HIVST acceptability among MSM and TGW in different settings (Figueroa C et al., 2015; Freeman AE et al., 2018; Gohil J et al., 2020; Krause J et al., 2013; Pai NP et al., 2013; Wirtz AL et al., 2016). This is encouraging in the light of continuing COVID-19 pandemic and an uncertain future with regards to access to facility-based HIV testing services it has created.

Our study revealed participants' ambiguous attitudes toward the privacy of HIVST. On the one hand, when interpreted in terms of anonymity, it was perceived as one of the main advantages of self-testing; MSM and TGW stressed the ability to avoid stigma related to HIV, as well as to gay identity by using self-tests at home instead of visiting medical facilities. Thus, its empowering potential in the context of high stigmatization of LGBTQ-people in Russia was emphasized. On the other hand, when discussing the possibility of receiving a reactive result some informants expressed need for immediate personal support and, therefore, perceived privacy as a drawback. Of note, this need for support was not medicalized when speaking about receiving a positive result participants stressed the importance of presence of someone, who is supportive and aware of LGBTQ-identity of the user and not necessarily a health care professional. While the ambiguity of attitudes towards privacy of HIVST is consistent with findings of previous research on the topic (Freeman AE et al., 2018; Liu F et al., 2019; Pai NP et al., 2013; Wirtz AL et al., 2017) this project provides additional evidence for the empowering potential that HIVST may have for MSM and TGW in countries with high stigmatization of LGBTQ.

A perceived lack of accuracy of saliva-based self-testing was the main concern reported by study participants. Some informants attributed this concern to a number of external factors, such as a possibility of making a mistake during the self-test performance, getting a defective kit or an invalid result. In addition, the majority of informants believed that HIV self-tests, and saliva-based self-tests in particular, are less accurate compared to 'traditional' blood-based HIV testing. The majority of identified issues correspond to concerns of participants in prior studies (Freeman AE et al., 2018; Pai NP et al., 2013; Witzel TC, Bourne A, et al., 2020); however, to our knowledge, a concern of getting a defective selftest kit has not been described to date. As our participants put more trust in blood-based results, more research is needed on comparative acceptability of blood-based vs. saliva-based HIVST. Interpretation of test results seems to be another issue : while all the participants described test instruction as simple and straightforward, many informants with reactive result reported confusion when interpreting the result of the test. Thus, the problem of reactive result misinterpretation is crucial in terms of linkage to care and treatment. 
Importantly, HIV self-kits in this study were distributed among the study participants free of charge. Thus, acceptability of paid HIV self-testing and affordability of prices for self-test kits (willingness to pay) for MSM and TGW are worth investigation for scaling up this procedure among these key groups in Russia.

On the basis of our study we would like to suggest the following recommendations for increase in uptake HIVST among MSM, TGW, and possibly other groups, who would benefit from this testing procedure:

First, information about HIVST technology should be popularized as there is evidence that lack of knowledge about HIVST existence and the working principles behind it affects trust in the accuracy of this method. Second, it is of crucial importance to make sure that potential users of HIVST are wellinformed about the visual variability of test results in terms of transparency and sharpness of the lines. Third, post-test counseling should be available, especially for those users who feel the need of immediate personal support when receiving a reactive result or feel uncertain about the test result - to help users link to care and engage in the HIV treatment cascade.

The study has several limitations. First, the study aimed to examine attitudes of both MSM and TGW, however, during the recruiting phase it became apparent that it was challenging to recruit a sufficient number of TGW informants. Therefore, the sample mostly consisted of MSM, which makes generalizing results to TGW (even in qualitative terms) questionable and requires future studies to focus more on TGW group. Second, our informants were mostly highly educated and working, therefore, the findings may be less relevant for MSM and TGW with other demographics. Recall and social desirability bias is another limitation of this study.

\section{Declarations}

The authors have no competing interests to declare.

\section{Acknowledgements}

We would like to acknowledge that NGO 'Phoenix PLUS' and Safe Box project supported by the Elton John Foundation. The publication was prepared within the framework of the Academic Fund Program at the National Research University Higher School of Economics (HSE) in 2020 (grant №_20-01-061_) and by the Russian Academic Excellence Project "5-100".

\section{References}

AFEW. (2020). At our own risk. EECA'S response to COVID-19. http://afew.org/covid-19/at-our-own-riskeecas-reponse-to-covid-19/ Accessed on 15 May 2020.

Allais L, \& Venter F. (2014). The Ethical, Legal and Human Rights Concerns Raised by Licensing HIV SelfTesting for Private Use. AIDS and Behavior, 18(4), 433-437. 
Amirkhanian YA, Kelly JA, Kirsanova AV, \& et al. (2006). HIV risk behaviour patterns, predictors, and sexually transmitted disease prevalence in the social networks of young men who have sex with men in St Petersburg, Russia. International Journal of STD \& AIDS, 17(1), 50-56.

Bavinton BR, Brown G, Hurley M, \& et al. (2013). Which Gay Men Would Increase Their Frequency of HIV Testing with Home Self-testing? AIDS and Behavior, 17(6), 2084-2092.

Berg, R. C., Skogen, V., Vinogradova, N., Beloglazov, A., \& Kazantseva, T. (2017). Predictors of HIV Risk Behaviors Among a National Sample of Russian Men Who Have Sex with Men. AIDS and Behavior, 21(10), 2904-2912. https://doi.org/10.1007/s10461-016-1653-x

Berg RC, Skogen V, Vinogradova N, Beloglazov A, \& Kazantseva T. (2017). Predictors of HIV Risk Behaviors Among a National Sample of Russian Men Who Have Sex with Men. AIDS and Behavior, 21(10), 2904-2912.

Beyrer C, Wirtz AL, O'Hara G, Léon N, \& Kazatchkine M. (2017). The expanding epidemic of HIV-1 in the Russian Federation. PLOS Medicine, 14(11).

Braun V, Clarke V, Hayfield N, \& Terry G. (2019). Thematic analysis. In Handbook of research methods in health social sciences (pp. 843-860).

Brito MO, Khosla S, Santana L, \& et al. (2020). A community-based model of HIV care for men who have sex with men and transgender women in Chicago. International Journal of STD \& AIDS, 31(2), 150-157.

Bustamante MJ, Konda KA, Davey DJ, \& et al. (2017). HIV self-testing in Peru: Questionable availability, high acceptability but potential low linkage to care among men who have sex with men and transgender women. International Journal of STD \& AIDS, 28(2), 133-137.

Buyantueva R. (2018). LGBT rights activism and homophobia in Russia. Journal of Homosexuality, 65(4), 456-483.

Campbell CK, Lippman SA, Moss N, \& Lightfoot M. (2018). Strategies to increase HIV testing among MSM: a synthesis of the literature. AIDS and Behavior, 22(8), 2387-2412.

Clark JL, Konda KA, Silva-Santisteban A, \& et al. (2014). Sampling methodologies for epidemiologic surveillance of men who have sex with men and transgender women in Latin America: An empiric comparison of convenience sampling, time space sampling, and respondent driven sampling. AIDS and Behavior, 18(12), 2338-2348.

The Centers for Disease Control and Prevention (CDC). (2020). HIV Self Testing Guidance. https://www.cdc.gov/nchhstp/dear_colleague/2020/dcl-042820-HIV-self-testing-guidance.html Accessed 14 May 2020. 
Figueroa C, Johnson C, Verster A, \& Baggaley R. (2015). Attitudes and Acceptability on HIV Self-testing Among Key Populations: A Literature Review. AIDS and Behavior, 19(11), 949-965.

Freeman AE, Sullivan P, Higa D, \& et al. (2018). Perceptions of HIV Self-Testing Among Men Who Have Sex With Men in the United States: A Qualitative Analysis. AIDS Education and Prevention, 30(1), 47-62.

Frye V, Wilton L, Hirshfield S, \& et al. (2015). "Just Because It's Out There, People Aren't Going to Use It." HIV Self-Testing Among Young, Black MSM, and Transgender Women. AIDS Patient Care and STDS, 29(11), 617-624.

Gama A, Martins MO, \& Dias S. (2017). HIV research with men who have sex with men (MSM): Advantages and challenges of different methods for most appropriately targeting a key population. AIMS Public Health, 4(3), 221.

Gohil J, Baja ES, Sy TR, \& et al. (2020). Is the Philippines ready for HIV self-testing? BMC Public Health, 20(1), 1-8.

Greacen T, Friboulet D, Blachier A, \& et al. (2013). Internet-using men who have sex with men would be interested in accessing authorised HIV self-tests available for purchase online. AIDS Care, 25(1), 49-54.

Hakim AJ, Coy K, Patnaik P, \& et al. (2018). An urgent need for HIV testing among men who have sex with men and transgender women in Bamako, Mali: Low awareness of HIV infection and viral suppression among those living with HIV. PLOS ONE, 13(11).

HIV infection in the Russian Federation, 2014 [Internet]. [Cited 2014 Nov 4]. Available from: Http://www.hivrussia.ru/files/spravkaHIV2014.pdf. Accessed 1 April 2018. (n.d.).

The International AIDS Society (IAS) (2020). Test, test, test: COVID-19 and HIV testing updates. https://www.iasociety.org/Web/WebContent/File/EduFund/COVIDwebinars/3Presentation_RachelBaggaley.pdf Accessed 14 May 2020.

Iribarren SJ, Ghazzawi A, Sheinfil AZ, \& et al. (2018). Mixed-method evaluation of social media-based tools and traditional strategies to recruit high-risk and hard-to-reach populations into an HIV prevention intervention study. AIDS and Behavior, 22(1), 347-357.

Krause, J., Subklew-Sehume, F., Kenyon, C., \& Colebunders, R. (2013). Acceptability of HIV self-testing: A systematic literature review. BMC Public Health, 13, 735. https://doi.org/10.1186/1471-2458-13-735

Krause J, Subklew-Sehume F, Kenyon C, \& Colebunders R. (2013). Acceptability of HIV self-testing: A systematic literature review. BMC Public Health, 13, 735.

Lippman SA, Lane T, Rabede O, \& et al. (2018). High Acceptability and Increased HIV-Testing Frequency After Introduction of HIV Self-Testing and Network Distribution Among South African MSM. Journal of Acquired Immune Deficiency Syndromes, 77(3), 279-287. 
Lippman SA, Moran L, Sevelius J, \& et al. (2016). Acceptability and Feasibility of HIV Self-Testing Among Transgender Women in San Francisco: A Mixed Methods Pilot Study. AIDS and Behavior, 20(4), 928-938.

Liu F, Qin Y, Meng S, \& et al. (2019). HIV self-testing among men who have sex with men in China: A qualitative implementation research study. Journal of Virus Eradication, 5(4), 220.

Martinez, O., Carballo-Diéguez, A., Ibitoye, M., Frasca, T., Brown, W., \& Balan, I. (2014). Anticipated and Actual Reactions to Receiving HIV Positive Results Through Self-Testing Among Gay and Bisexual Men. AIDS and Behavior, 18(12), 2485-2495. https://doi.org/10.1007/s10461-014-0790-3

Napierala Mavedzenge, S., Baggaley, R., \& Corbett, E. L. (2013). A Review of Self-Testing for HIV: Research and Policy Priorities in a New Era of HIV Prevention. Clinical Infectious Diseases, 57(1), 126-138. https://doi.org/10.1093/cid/cit156

Oldenburg CE, Biello KB, Perez-Brumer AG, \& et al. (2017). HIV testing practices and the potential role of HIV self-testing among men who have sex with men in Mexico. International Journal of STD \& AIDS, 28(3), 242-249.

Pai NP, Sharma J, Shivkumar S, \& et al. (2013). Supervised and Unsupervised Self-Testing for HIV in Highand Low-Risk Populations: A Systematic Review. PLOS Medicine, 10(4), e1001414.

Plavinskiy SL, Ladnaya NN, Zaytseva EE, \& Barinova AN. (2018). HIV prevalence among vulnerable groups in Russia-Results of an integrated bio-behavioral survey. Zhurnal Mikrobiologii Epidemiologii $i$ Immunobiologii, 6, 10-18.

Pokrovsky V, Nladnaia N, \& Pokrovskaya A. (2017). HIV/AIDS is reducing the number of Russians and their life expectancy. Demographic Review, 4(5).

Rosengren AL, Huang E, Daniels J, Young SD, Marlin RW, \& Klausner JD. (2016). Feasibility of using GrindrTM to distribute HIV self-test kits to men who have sex with men in Los Angeles, California. Sexual Health, 13(4), 389-392.

Stannah J, Dale E, Elmes J, \& et al. (2019). HIV testing and engagement with the HIV treatment cascade among men who have sex with men in Africa: A systematic review and meta-analysis. The Lancet HIV, 6(11), 769-787.

Stuikyte R, Barbosa I, \& Kazatchkine M. (2019). Getting to grips with the HIV epidemic in Russia. Current Opinion in HIV and AIDS, 14(5), 381-386.

Vasquez C, Lioznov D, Nikolaenko S, \& et al. (2013). Gender disparities in HIV risk behavior and access to health care in St. Petersburg, Russia. AIDS Patient Care and STDs, 27(5), 304-310.

VERBI Software. (2019). MAXQDA 2020. VERBI Software. https://www.maxqda.com/ 
Walensky RP, \& Bassett IV. (2011). HIV Self-testing and the Missing Linkage. PLOS Medicine, 8(10), e1001101.

Wei C, Yan L, Lippman SA, \& et al. (2018). Prevalence and correlates of point-of-sex human immunodeficiency virus self-testing among human immunodeficiency virus-negative men who have sex with men in China. Sexually transmitted diseases. Sexually Transmitted Diseases, 45(12), 818-822.

WHO / Consolidated guidelines on HIV testing services (pp. 1-14). (2014).

http://www.who.int/hiv/pub/guidelines/hiv-testing-services/en/

Wirtz AL, Clouse E, Veronese V, \& et al. (2017). New HIV testing technologies in the context of a concentrated epidemic and evolving HIV prevention: Qualitative research on HIV self-testing among men who have sex with men and transgender women in Yangon, Myanmar. Journal of the International AIDS Society, 20(1), 21796.

Wirtz AL, Zelaya CE, Latkin C, \& et al. (2016). The HIV care continuum among men who have sex with men in Moscow, Russia: A cross-sectional study of infection awareness and engagement in care. Sexually Transmitted Infections, 92(2), 161-167.

Wirtz AL, Zelaya CE, Peryshkina A, \& et al. (2014). Social and structural risks for HIV among migrant and immigrant men who have sex with men in Moscow, Russia: Implications for prevention. AIDS Care, 26(3), 387-395.

Witzel TC, Bourne A, Burns FM, \& et al. (2020). HIV self-testing intervention experiences and kit usability: Results from a qualitative study among men who have sex with men in the SELHPI (Self-Testing Public Health Intervention) randomized controlled trial in England and Wales. HIV Medicine, 21(3), 189-197.

Witzel TC, Gabriel MM, McCabe L, \& et al. (2019). Pilot phase of an internet-based RCT of HIVST targeting MSM and transgender people in England and Wales: Advertising strategies and acceptability of the intervention. BMC Infectious Diseases, 19(1), 1-3.

Witzel TC, Weatherburn P, Bourne A, \& et al. (2020). Exploring Mechanisms of Action: Using a Testing Typology to Understand Intervention Performance in an HIV Self-Testing RCT in England and Wales. International Journal of Environmental Research and Public Health, 17(2), 466.

Wood BR, Ballenger C, \& Stekler JD. (2014). Arguments for and against HIV self-testing. HIV/AIDS (Auckland, N.Z.), 6, 117-126.

Zhang, C., Li, X., Brecht, M.-L., \& Koniak-Griffin, D. (2017). Can self-testing increase HIV testing among men who have sex with men: A systematic review and meta-analysis. PLOS ONE, 12(11), e0188890. https://doi.org/10.1371/journal.pone.0188890

Zhu X, Zhang W, Operario D, \& et al. (2019). Effects of a Mobile Health Intervention to Promote HIV Selftesting with MSM in China: A Randomized Controlled Trial. AIDS and Behavior, 23(11), 3129-3139. 